\title{
A fruitful approach towards reduction in pollutants from internal combustion engines through nanotechnology
}

\author{
Raghav Dosi ${ }^{*}$, Moiz Modi and Pawan Sharma \\ Department of Mechanical Engineering, VIT (East), Jaipur, India \\ *Email: shonidosik@gmail.com
}

With an exponential rise in population and living standards, the transportation sector is consuming large amount of fuel combustion. This requires an urgent need for research and development in the emission control from IC Engines and regarding this, nanotechnology will be the optimum option. In this paper, various methods to reduce the emission of pollutants are investigated with effective synthesis. It also includes the ways through which the ambient air quality control can be done. The major pollutants contributed by IC engines are $\mathrm{CO}, \mathrm{NOX}$, less burnt hydro carbons and other particulate emissions depending upon the source and type of combustion process. There are some other sources viz. Industrial and domestic fuel consumptions, Power stations etc. also generating the pollutants at an alarming rate. With the conventional pollution standards by the Government of India as stated in environmental protection act (EPA), 1986 and pollution control act, 1992 require an urgent review. There are much kind of toughest challenges encounter by mankind is due to the environmental imbalance and abrupt increase in greenhouse effect. The major source of pollution can be found in automobiles; among them two wheelers is one of the main causes. The pollution control methods can be identified under two categories i.e. pre pollution control and post pollution control. This paper consists of post pollution control method in which two wheeler automobiles using nanoparticles as a catalyst is scrutinized.

A study on nanoparticles reveals that the ratio of surface area of nanoparticle to its volume is inversely proportional to the radius of the nanoparticle. So, on decreasing the radius of nanoparticle, the ratio is increased leading to an increased rate of reaction which ultimately tends to decrease in the concentration of pollutants.

In order to achieve this objective, a catalytic convertor using nanoparticles as a catalyst with an innovative design is recommended (Figure
2). It includes copper nanoparticles (Figure 2) which has the major advantages over platinum, palladium and rhodium which are the conventional sources used in the automobiles. It has been analyzed that nanoparticles can play a vital role in the enhancement of heat transfer rate due to its small size. This temperature gradient can be further intensified with the help of waste heat recovery. This will be responsible in increase in thermal efficiency and optimization of the suggested design by means of more utilization of fuel in an automobile. As a result, heat recovery from the IC engine with its utilization at a proper rate and place and the nanotechnology shall be the best techniques in upcoming automobile application which can save both the fossil fuel as well as the environment.

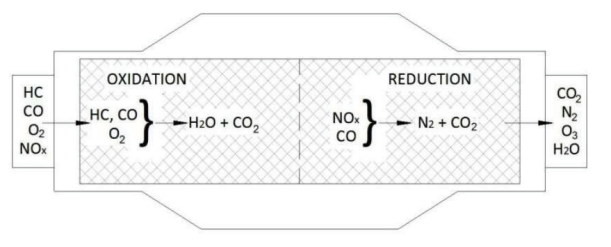

Figure 1: Oxidation and reduction processes in catalytic converter
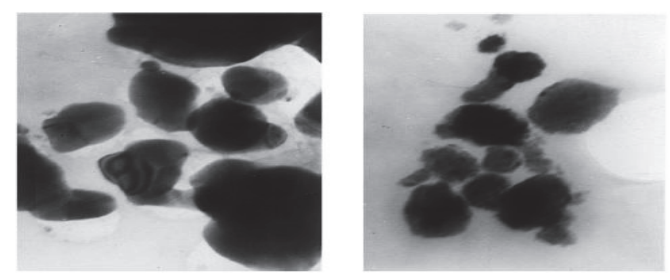

Figure 2: Micrographs of Copper nanoparticles

\section{References}

1. Juhi saraf, "IJERA", Exhaust emissions and its control technology for an IC engine, ISSN: 22489622, vol.3, issue 4, (2013), pp. 947-960

2. Raghav Dosi, Pawan sharma, "IJAB", An Integrated approach, applications and enhancement of Nanofluids in Heat Transfer, ISSN: 0973-9084, vol. 9, (2015), pp. 10-14 